\title{
Mediação da leitura com o idoso: perspectivas a partir da literatura científica da Ciência da Informação
}

\author{
Mediation of reading with the elderly: perspectives from the scientific literature of \\ information science
}

\author{
Fausto José Silva Calheira \\ Mestre em Ciência da Informação pela Universidade Federal da Bahia - UFBA, Brasil. \\ Bibliotecário da Escola SESI - Candeias, Brasil. \\ E-mail: fausto_calheira@hotmail.com
}

\begin{abstract}
Raquel do Rosário Santos
Doutora em Ciência da Informação pela Universidade Federal da Paraíba - UFPB, Brasil. Professora Adjunta do Instituto de Ciência da Informação da Universidade Federal da Bahia - UFBA, Brasil.

E-mail: quelrosario@gmail.com
\end{abstract}

\section{Resumo}

A população idosa tem crescido cada vez mais. Esse fenômeno é oriundo de diferentes fatores, dentre eles, o aumento da expectativa de vida e o avanço da Medicina. Com base nessas inferências, é necessário adotar práticas que possam contribuir para melhorar a qualidade de vida na terceira idade. $\mathrm{O}$ ato de ler e sua dinâmica possibilitam que os idosos possam formar novos conceitos sobre o mundo em que vivem, sobretudo, o papel que desempenham na sociedade e na família. Dessa maneira, a mediação da leitura torna-se relevante ao proporcionar bem-estar e ajudar os idosos a superarem problemas de comunicação e de interação. Nessa perspectiva, o objetivo desta pesquisa foi analisar, com base na literatura da Ciência da Informação, como a mediação da leitura pode contribuir com a vida sociocultural do idoso. Quanto à metodologia, trata-se de uma pesquisa bibliográfica que se pauta nos estudos da Ciência da Informação sobre a mediação da leitura voltada aos idosos. Considerando as reflexões apresentadas sobre a mediação da leitura, entende-se que ela é sobremaneira importante na vida dos idosos e pode colaborar para o processo de inclusão social e bem-estar. Constatou-se também que a mediação da leitura associada a um bom planejamento pode colaborar com a qualidade de vida do idoso, trazendo benefícios para o biopsicossocial desses sujeitos.

Palavras-chave: Mediação da leitura. Mediação da informação. Leitura com idoso. Instituições de Longa Permanência para Idosos (ILPI).

\begin{abstract}
The elderly population has been growing more and more. This phenomenon is caused by different factors, including the increase in life expectancy and the advancement of Medicine. Based on these inferences, it is necessary to adopt practices that can contribute to improving the quality of life in old age. The act of reading and its dynamics enable the elderly to form new concepts about the world in which they live, above all, the role they play in society and in the family. Thus, the mediation of reading becomes relevant to provide well-being and help the elderly to overcome communication and interaction problems. From this perspective, the objective of this research was to analyze, based on the literature of Information Science, how the mediation of reading when performed in a conscious and humanized manner, which questions and processes the meaning of the text, projecting its worldview on it. critical, can contribute to the sociocultural life of the elderly. As for the methodology, it is a bibliographical research that is based on Information Science studies on the mediation of reading aimed at the elderly. Considering the reflections presented on the mediation of reading, it is understood that it is extremely important in the lives of the elderly and can contribute to the process of social inclusion and well-being. It was also found that the conscious mediation of reading, associated with good planning, can collaborate with the quality of life of the elderly, bringing benefits to the biopsychosocial of these subjects.
\end{abstract}

Keywords: Reading mediation. Information mediation. Reading with the elderly. Long-stay Institutions for the Elderly (ILPI).

InCID: R. Ci. Inf. e Doc., Ribeirão Preto, v. 12, n. 2, p. 109-125, set. 2021./fev. 2022.

DOI: 10.11606/issn.2178-2075.v12i2p109-125 


\section{Introdução}

A população idosa vem aumentando a cada ano. De acordo com a estimativa de projeções populacionais baseadas no Censo do IBGE (INSTITUTO BRASILEIRO DE GEOGRAFIA E ESTATÍSTICA, 2007), o número de brasileiros com idades acima de 65 anos deve quadruplicar até 2060, o que confirma a tendência de envelhecimento acelerado da população já apontada por demógrafos. Portanto, é necessário discutir sobre assuntos que circundam a melhoria da qualidade de vida nessa faixaetária.

Para compreender como as atividades de mediação da leitura podem ocorrer de maneira mais humanizada, conduzindo ao protagonismo social, é preciso um olhar mais atento aos sujeitos que participam dessa ação. No âmbito desta pesquisa, que corresponde a um fragmento da pesquisa em desenvolvimento no curso de mestrado em Ciência da Informação, que versa sobre a mediação da leitura com o idoso no âmbito das instituições de longa permanência, discute-se sobre como as práticas de leitura e sua mediação podem contribuir com a vida e o bem-estar físico, psíquico e social do idoso, como também as reflexões na área da Ciência da Informação sobre essas práticas. Diante do exposto, esta comunicação teve como objetivo analisar, com base na literatura da Ciência da Informação, como a mediação da leitura pode contribuir com a vida sociocultural do idoso.

Quanto ao delineamento metodológico pode-se caracterizar esta pesquisa como descritiva de natureza qualitativa, que de acordo com Gil (2010, p. 27), “[...] têm como objetivo a descrição das características de determinada população ou fenômeno ou, então, o estabelecimento de relações entre variáveis." Assim, esta comunicação analisa os aspectos basilares da mediação da leitura que são abordados na literatura científica da Ciência da Informação e os relaciona com as possíveis contribuições para os idosos, refletidas em estudos da área supracitada. No que se refere aos procedimentos, esta pesquisa se caracteriza como bibliográfica, que para Gil (2010) é realizada com base em textos científicos. Vale destacar que a pesquisa em tela não visa um levantamento quantitativo dos textos que tratam sobre a mediação da leitura, mas busca por meio de estudos reconhecidos pela comunidade retomar a discussão de elementos norteadores do processo mediador que podem apoiar no avanço de reflexões sobre a temática em questão voltada aos idosos. 


\section{Contribuições da mediação da leitura para a vida do sujeito idoso} da Informação

A leitura pode propiciar lazer e descontração, ampliar informações e conhecimentos e, até, subsidiar o tratamento de problemas emocionais. Rasteli (2013, p. 14) enuncia que, “[...] atualmente, a leitura é reconhecida como uma atividade significativa, levando em consideração a participação do indivíduo como possuidor de uma história individual e singular em seu processo de apreensão cultural." A leitura e as ações que derivam dela variam conforme os sujeitos que as realizam. Assim, os agentes que planejam e executam ações voltadas para a leitura devem perceber e considerar os sujeitos e seus aspectos singulares.

Segundo Boso e colaboradores (2010, p. 24), “A leitura é um importante instrumento para a vida social e cognitiva do sujeito, o que qualifica sua inserção no âmbito social, político, econômico e cultural." Isso significa que a leitura é uma ação necessária para a realização de todas as atividades sociais, que opera de maneira individual e coletiva, e favorece a interação social e cultural, além de acionar os elementos biopsicossociais. A leitura proficiente - a que se realiza de maneira crítica -pode despertar no sujeito pensamentos, falas e atitudes que estão envolvidos com esquemas mentais que lhes proporcionam a capacidade de entender e interferir diretamente na maneira como se expressam e se comunicam com os outros. Isso possibilita compreender bem mais a relação existente entre os sujeitos e omundo.

É por meio das atividades de mediação da leitura propostas e desenvolvidas pelo mediador que o sujeito poderá sentir a ludicidade que o texto proporciona. A mediação da leitura também contribui com o processo de (re)construção do conhecimento e, ao mesmo tempo, visa proporcionar uma autonomia diante da interpretação e das emoções que são geradas no momento da leitura.

\footnotetext{
A leitura não pode mais ser vista como simples meio de decodificação de mensagem, pois é elemento essencial no avanço de uma sociedade em pleno desenvolvimento. A compreensão de textos faz com que as pessoas tenham acesso a novas experiências e novas informações que ajudam a ampliar seus conhecimentos intelectuais e sociais. (BOSO et al., 2010, p. 28).
}

Com as contribuições das atividades de mediação da leitura para os sujeitos, são fundamentais a participação e o comprometimento do mediador e do mediado. Essa é uma ação ressignificada constantemente pelas necessidades e pelos objetivos dos sujeitos que integram o processo de mediação da leitura. Os mediadores da leitura, que tanto podem ser os membros da família quanto os profissionais que atuam nos campos da Informação, da Educação e da Cultura, devem entender que suas ações influenciam os sujeitos para quem as atividades de mediação 
da leitura estão sendo desenvolvidas e são influenciadas por eles. Cabe ao segundo grupo - o de profissionais das diversas áreas que atuam como mediadores da leitura - atuar nessa perspectiva e apoiar os sujeitos, informalmente ou no ambiente do lar, com a família, de modo que o processo de mediação da leitura contribua efetivamente na qualidade de vida desses sujeitos.

$\mathrm{Na}$ epistemologia vygotskyana, a interação se caracteriza pelo paradigma do sujeito interativo diferenciado do paradigma do sujeito passivo. Para Vygotsky, a interação entre os sujeitos não se estabelece somente na dimensão intersubjetiva, isto é, a dimensão do outro, mas na dimensão da relação com o outro. (MORO; ESTABEL, 2011, p. 69).

$\mathrm{O}$ ato de ler pode favorecer a obtenção de respostas para as situações que cercam os sujeitos e conduzi-los a observar com mais vivacidade as circunstâncias do cotidiano. Quando a leitura é estimulada desde a infância, na vida adulta, essa ação poderá se manter como um prazer constante, o que garante ao leitor a aquisição de senso crítico nas mais variadas temáticas que envolvem a vida em sociedade.

A leitura pode ser apresentada aos sujeitos desde os primeiros anos de vida, quando eles têm contato com ela por meio do acolhimento familiar e é incentivado pela escola. No âmbito familiar, a mediação pode ocorrer com a leitura de um livro literário ou por meio da oralidade. Exemplos disso são as histórias que deram origem à família, os encontros entre os entes queridos ou a migração para espaços geográficos distintos. As narrativas familiares proporcionam à criança o conhecimento e podem despertá-la para adquirir novas informações. Na escola, a leitura pode ocorrer por meio de múltiplos dispositivos, quando a prática da leitura é iniciada com o objetivo de favorecer o acesso à informação e apoiar a produção escrita.

Na vida adulta, a leitura vai ficando cada vez mais complexa e pode auxiliar os sujeitos a entenderem o mundo onde estão inseridos. A partir desse momento, o leitor também vai desenvolvendo a necessidade de entender e contextualizar as situações ao seu redor, o que dá origem a uma leitura que analise, questione e processe o significado do texto, projetando sobre ele sua visão de mundo para estabelecer uma interação e interpretação crítica com o que foi lido. De acordo com Santos (2006, p. 29), “[...] ler, antes de tudo, é descobrir e expandir horizontes, porém ler apenas como um decifrar dos sentidos dos signos pareceautomatismo."

A leitura pode ser entendida de diferentes maneiras e possibilitar diversas formas de diálogo e dinâmicas entre os leitores e possíveis mediadores. Por meio da leitura e suas diferentes possibilidades, descobrem-se novas formas de lazer e de integração social. Contudo, para que isso ocorra satisfatoriamente, são necessárias ludicidade e estratégias que possibilitem 
ao leitor mais atratividade e prazer. Essas características colocam a leitura em uma posição de modificadora social, porque pode interferir diretamente nas relações humanas e na conduta das pessoas e apoia o desenvolvimento das capacidades intelectuais e o senso crítico dos sujeitos. Assim, a leitura pode ajudar o sujeito a desenvolver a criatividade em relação ao próprio meio e ao meioexterno.

Freire (2008) assevera que "A leitura do mundo precede a leitura da palavra, daí que a posterior leitura dessa não possa prescindir da continuidade da leitura daquele. Linguagem e realidade se prendem dinamicamente." Essa citação denota que a leitura de livros, de revistas e de jornais precede a leitura da vida. Isso significa que, ao ler ou escutar um texto, o sujeito assume uma posição diante dele e passa a fazer conjecturas a respeito do que leu.

A partir das experiências individuais, o leitor pode interpretar distintamente determinada situação, pautado nos padrões da construção de ideias em que foi inserido.

Assim a produção de leitura consiste no processo de interpretação desenvolvido por um sujeito-leitor que, defrontando-se com um texto, analisa e questiona, com o objetivo de processar seu significado projetando sobre ele sua visão de mundo para estabelecer uma interação crítica com o texto. (INDURSKY; ZINN, 1985, p. 56).

Há que se ressaltar que a leitura interfere no modo de agir e nas relações humanas, razão por que é fundamental nas diferentes fases da vida. Ela ajuda a desenvolver determinadas competências que aguçam o processo de criatividade e de reflexão crítica do cidadão e contribui não só para desenvolver o senso crítico, como também para estimular o sistema nervoso central e toda a parte neuronal. Essa circunstância vai distinguir os sujeitos, especialmente no processo de envelhecimento.

É importante que o mediador entenda que, como o conceito de leitura é amplo, ela pode ser feita de diferentes formas. Uma pessoa pode ler um texto escrito, uma pintura ou a melodia de uma canção. A leitura também pode ser realizada por sujeitos de diferentes contextos e realidades sociais que demandam atenções diferentes, na coletividade, por sujeitos distintos que se unem pelo mesmo objetivo, ou na individualidade, com um mesmo sujeito que se distingue em suas fases da vida.

Ao tratar da leitura e de sua mediação para a pessoa idoso é preciso refletir que ainda existe muito preconceito na sociedade. Com o passar dos anos, essas pessoas podem sofrer um processo de "desinserção social" e perder os vínculos e os laços que construíram ao longo da vida. Nesse contexto, as atividades direcionadas à leitura podem ser valiosas em seu processo de sociabilização. Bortolin (2010), ao tratar da mediação da leitura, defende que, associada ao 
lazer, essa ação é uma forma de resgatar a cidadania, minimizar as desigualdades sociais e as injustiças e melhorar a convivência na família e na comunidade.

As práticas de leitura com a população idosa são importantes e imprescindíveis nas políticas de inclusão, visto que contribuem para melhorar a qualidade de sua vida e proporcionam bem-estar físico, psíquico e social. São muitas as ações que envolvem a leitura e podem contribuir para o cotidiano das pessoas idosas e, consequentemente, ser desenvolvidas em diferentes dispositivos sociais, como as Instituições de Longa Permanência para Idosos (ILPI), por exemplo.

As atividades de mediação da leitura abarcam diferentes modalidades e recursos para garantir um resultado efetivo. Também vale ressaltar sobre a importância de compreender a diferença que o público idoso apresenta e ter consciência dos objetivos que desejam alcançar e os meios para efetivar essasações. Essa perspectiva alcança consenso com os estudos de Rêgo e Sampaio (2014), que afirmam que, se o mediador utilizar o espaço adequadamente, vai desempenhar um papel muito importante na mediação da leitura.

Essas atividades de mediação da leitura podem despertar nos idosos vários sentimentos e sensibilidade para refletir sobre suas questões pessoais. Por isso, no planejamento das ações de mediação da leitura, é imprescindível analisar e selecionar criteriosamente as atividades que serão realizadas e o material a ser utilizado, considerando também os procedimentos para conduzir essas atividades. Para Orlickas (2010), o planejamento tem o propósito de prever e reduzir tudo o que possa inibir o resultado final esperado e aumentar todas as possibilidades de facilitar o processo de tomada de decisão, proporcionando decisões mais assertivas.

Ainda sobre a relevância de planejar as atividades de mediação da leitura, Cunha (1996) afirma que essa atividade envolve os processos de criação e de ação. Dessa forma, a mediação da leitura voltada para os idosos pode ter como perspectiva a promoção do lazer e do entretenimento. A mediação da leitura proporciona bem-estar, pois ajuda os idosos a superarem problemas de comunicação e de interação. Essas ações também podem ser voltadas para incluílos e mantê-los na sociedade, especialmente no mundo do trabalho, porquanto colaboram para o acesso à informação, ampliam seu vocabulário, desenvolvem o intelecto e resgatam a autoestima. Como consequência, eles passam aatribuir (ou reatribuir) sentido à sua vida. Assim, essas ações envolvem diversas atividades, com técnicas e métodos diversos, a fim de atingir os objetivostraçados. 
O uso da leitura e sua dinâmica possibilitam que os idosos possam formar novos conceitos sobre o mundo em que vivem, sobretudo, o papel que desempenham na sociedade e na família. Thomaz e Valência (2012, p. 148) referem que "[...] a experiência da leitura envolve diferentes processos em sua prática e sua forma de ler, por isso é uma importante ferramenta de inclusão, que contribui para que o idoso fortaleça sua condição de ser cidadão.” A leitura é um estímulo cultural na vida dos sujeitos, porque lhes proporciona lazer, possibilita que participem de diferentes atividades, resgatem a memória e construam novos laços afetivos, direcionandoos a se reconhecerem como cidadãos. Essa condição é importante para eles, porque,

\begin{abstract}
[...] ao chegar à velhice ou se aposentarem, enfrentam um período de adaptação à nova realidade, muitas vezes difícil e que pode trazer sentimentos diversos, sendo de fundamental importância o apoio de familiares e amigos, de modo que possam mostrar-lhes que suas vidas têm sentido sempre e que agora, apenas estão tendo um descanso merecido por todo o esforço e dedicação ao longo de suas vidas, com a oportunidade de aproveitá-la e fazendo perceber que os valores de caráter do ser humano são justamente mais aprimorados na fase em que estão: na melhor idade. (JERÔNIMO et al., 2012, p. 465).
\end{abstract}

As diferenças apresentadas na terceira idade requerem um direcionamento das práticas realizadas na mediação da leitura que devem se adequar ao meio em que o idoso está inserido. $\mathrm{Na}$ terceira idade, as realidades são distintas, mas é importante entender que a atividade que envolve a mediação da leitura pode contribuir para melhorar a sociabilização da comunidade idosa, independentemente do ambiente em que ela vive. Também podem melhorar a capacidade do idoso de interpretar e exercitar sua memória, uma condição primordial nessa fase davida.

$\mathrm{Na}$ leitura, desenvolvida em seus diferentes aspectos, o leitor entra em contato com os saberes de quem escreveu o texto, adquire novos conhecimentos, renova seus saberes e ressignifica suas emoções. Assim,

As atividades de mediação e de fomento à leitura feitas por meio de visitas ou outras atividades educativas e recreativas proporcionam que o idoso esteja em constante contato com o mundo, construindo conhecimento, lendo por meio da narrativa oralizada e verbalizando suas histórias, revivendo emoções, sentindo e se comunicando de diversas formas com as demais pessoas. (GIACUMUZZI et al., 2014, p. 3).

É por meio dessas técnicas que o idoso pode interagir com o mediador ou com o grupo de pessoas com quem convive e, consequentemente, exercitar sua memória que, nessa fase da vida, merece atenção. Dessa forma, pode agregar conhecimentos, passar suas experiências e sentir emoções que ainda não foram experimentadas.

Independentemente do tipo de mediação da leitura escolhida para os idosos, elas podem lhes proporcionar uma nova visão da realidade e estimulá-los a encontrar alternativas para 
problemas que antes não sabiam como resolver. Nas instituições de longa permanência, por exemplo, o idoso pode vivenciar as atividades de mediação da leitura de maneira mais ampla, porque, muitas vezes, sente-se isolado devido à ausência da família. Então, as práticas de mediação da leitura podem impulsionar o convívio do idoso com os outros moradores, com os funcionários e com os mediadores.

\begin{abstract}
A leitura tem caráter modificador, entretanto, quando se mistura com as experiências de vida de cada indivíduo resulta em diferentes transformações. Alguns procuram na leitura as novas descobertas para aprimorar seus conhecimentos, outros buscam suas emoções e seus sentimentos descritos por um autor amigo e ainda há aqueles que procuram uma conversa consigo mesmo na leitura reflexiva, entretanto, para muitos idosos o pensar exprime um esforço que acreditam não possuírem mais razão para têlo, ou a leitura um lazer impossível por causa da cegueira ou do afastamento dos livros. (GIACUMUZZI et al., 2014, p. 8).
\end{abstract}

Muitos idosos sentem-se incapazes de desenvolver as atividades propostas, e isso pode inviabilizar o processo. Por essa razão, o mediador da leitura deve estar preparado para entender as divergências encontradas na população idosa e aplicar a melhor técnica de mediação da leitura para cada caso. Ressalte-se, contudo, que, apesar de todas as diferenças, a atividade de mediação é um fator propulsor de relações em qualquer idade. Bortolin (2010) refere que a sociabilização pode diminuir a carência social e afetiva. Isso significa que, com o exercício da leitura, os idosos se fortalecem, podem ter uma nova visão de mundo, e a qualidade de sua vida pode melhorar em diferentescontextos.

Considerando as reflexões apresentadas sobre a mediação da leitura, entende-se que ela é sobremaneira importante na vida dos idosos e pode colaborar para o processo de inclusão social e bem-estar. Por isso é importante saber como a literatura da Ciência da Informação vem contribuindo para a reflexão sobre as atividades de leitura voltadas para o indivíduoidoso. 


\section{Atividades de leitura com os idosos presentes na literatura da Ciência da Informação}

A literatura da Ciência da Informação apresenta contribuições relacionadas às possíveis ações da mediação da leitura realizadas com idosos ou que podem ser adaptadas para esse público específico. Essas ações podem variar de acordo com o perfil dos idosos, já que se pode entender a diversidade encontrada nessa população. Nesse contexto, é preciso considerar o perfil dos sujeitos, suas necessidades e os objetivos das ações para que se possa melhorar a qualidade de vida dos idosos no âmbito de uma ILPI. Os estudos apresentados a seguir podem ser entendidos como parâmetros de possíveis atividades, especialmente, as contribuições das ações de mediação da leitura para os sujeitos da terceiraidade.

A mediação da leitura pode ser aplicada no ambiente das ILPI porquanto proporciona bem-estar entre os idosos, melhora a sociabilidade e promove o contato entre gerações e entre os mediadores e eles.

A pesquisa de Thomaz e Valência (2012) reforça essa ideia, pois investigou um grupo de convivência - o "Grupo da Amizade" - que faz parte de um programa de serviço e amparo à terceira idade, suas características e sua relação com a sociedade. Um dos objetivos principais desse programa é de valorizar os idosos e incentivar sua participação na sociedade, com atividades culturais, esportivas e recreativas.

Outra pesquisa que trata das ações de mediação da leitura foi desenvolvida por Giacumuzzi e colaboradores (2014), que apresentam o projeto de leitura intitulado "Vivendo histórias: vivendo a inclusão por meio da leitura numa casa geriátrica", cujo objetivo foi de proporcionar a leitura como estímulo para o desenvolvimento emocional e intelectual dos idosos que vivem na Casa Lar do Cego Idoso. Para colocar em prática essas ações que proporcionam a acessibilidade e a inclusão social, são utilizados, por exemplo, contos, crônicas, poesias, diálogos dramatizados, dinâmicas de jogos e, principalmente, conversas entre os idosos e os voluntários. Por meio dessas ações de leitura, foi possível manter contato direto entre os idosos, por meio de conversas, perceber a formação de um vínculo afetivo entre eles, situação que foi verificada na percepção de que muitos idosos estão com mais disposição para outras atividades e para interagir com os demais moradores e funcionários da instituição.

Percebeu-se que as ILPI proporcionam uma assistência especializada, além dos cuidados diários de saúde que ajudam a melhorar a saúde física do idoso. É importante, ainda, que haja outras atividades para melhorar a qualidade de vida dessas pessoas, muitas das quais 
estão abandonadas e sem apoio familiar. Portanto, nessas instituições, devem ser desenvolvidas ações de inclusão social entre seus moradores. A mediação da leitura é uma forte aliada quando proporciona diferentes ações para esse fim.

Já no trabalho desenvolvido por Santos, Ribeiro e Sousa, em 2019, foram mapeadas as bibliotecas públicas estaduais localizadas na cidade de Salvador que têm um espaço próprio para os idosos. As autoras investigaram como as atividades de mediação eram direcionadas a eles e constataram que são feitas atividades como oficinas, contação de histórias e palestras e que, além de suprir necessidades informacionais com base no acervo, essas ações são uma forma de entretenimento que favorece a interação entre os idosos, que dialogam de maneira mais informal e descontraída sobre assuntos de seuinteresse.

Nessa mesma pesquisa, foram identificadas outras atividades de mediação da leitura, como oficinas de informática e de desenvolvimento humano, círculo de leitura e oficina de fotografia, que proporcionam o conhecimento dos recursos tecnológicos e potencializam o registro das informações e o acesso a elas. Segundo as autoras, as atividades de mediação da leitura são importantes porque, através de suas estratégias, os idosos são estimulados a interagir, a compartilhar experiências e a vivenciar um universo de novas aprendizagens, tornando-se indivíduos ativos e mais atuantes na sociedade atual.

As leituras, quando compartilhadas, auxiliam na percepção de outras formas de entender o entorno que vivemos, portanto, é uma forma de aprender e de conhecer pensamentos e ideias diferentes daquelas que estão arraigadas em nós e que ao passá-las para o exterior obtemos variadas interpretações e com isso, ganhamos em diversidade, em relatividade e muitas vezes, em igualdade de raciocínio (MELO; MORO; TRESSINO, 2011).

Outra pesquisa desenvolvida por Costa e Bortolin (2007) investigou de que forma e em quais unidades operacionais dos Departamentos Regionais do Serviço Social do Comércio (SESC) e do Serviço Nacional de Aprendizagem Comercial (SENAC) os bibliotecários estavam desenvolvendo ações de mediação da leitura voltadas para o idoso. Foram verificadas ações de leitura, como "Projetos Intergeracionais", que contam com a participação de crianças, jovens e idosos em diferentes atividades, como bate-papos, palestras e trabalhos de leitura em grupo utilizando uma linguagem acessível a todas as faixas etárias. Entre outras ações desenvolvidas para aproximar os leitores da leitura, podem-se citar os círculos de leitura, sessões de histórias, oficinas literárias e discussão sobre temas que atraiam o interesse de diferentes gerações. 
Na pesquisa supracitada, percebeu-se que as ações de leitura são importantes para as pessoas que frequentam essas Instituições, contudo ainda existem poucas iniciativas voltadas para os idosos em nosso país. Esse dado indica que é preciso melhorar a qualificação para as ações que são direcionadas à terceira idade, uma vez que esse sujeito ainda pode ser considerado ativo socialmente em diferentes aspectos.

\footnotetext{
Podemos entender a leitura como um processo permanente de comunicação interpessoal, algumas vezes mediada por um texto, independente da forma de seu suporte ou do seu conteúdo e, outras vezes, é efetuada diretamente de pessoa a pessoa. $\mathrm{E}$, nesse sentido, efetivamente, ela se torna um instrumento fundamental para a promoção da interação dos indivíduos no meio social, porque favorece o diálogo, a veiculação das ideias, as trocas simbólicas e os atos concretos de construção do ser individual e do ser social. (NEVES, 2007, p. 18).
}

Com base na reflexão de Neves (2007), entende-se que as ações de mediação da leitura são de grande importância quando pensadas em sua ação social dirigida ao idoso. Todas as atividades desenvolvidas podem estimular, de maneiras diferentes, os aspectos sociocognitivos dos idosos e melhorar o seu dia a dia.

Outro fator importante que deve ser considerado e é ligado às ações de mediação da leitura é a possibilidade de fazê-lo de maneira terapêutica, por meio da biblioterapia, em um grupo multidisciplinar. A biblioterapia utiliza a leitura com fins terapêuticos e, por conseguinte, exerce influência no modo de pensar, de agir e de se comportar das pessoas da terceira idade (PINHEIRO, 1998). Essa é mais uma ação que pode ser utilizada nas ILPI como mediadora daleitura.

Esse processo terapêutico pode auxiliar os idosos a refletirem sobre suas atitudes, as dores emocionais e os comportamentos, na perspectiva de ampliar a compreensão intelectual, de desenvolver o senso de pertencimento e de diminuir a ansiedade e a solidão. Nesse sentido, Jerônimo e outros autores (2012) apresentaram um relato das atividades de biblioterapia aplicada aos moradores idosos de um edifício residencial em São José (SC). As atividades desenvolvidas pela Professora Clarice Fortkamp Caldin foram a contação de histórias e uma dinâmica que consistia em distribuir crachás, fazer uma breve apresentação da biblioterapia e dos aplicadores e iniciar a dramatização de uma crônica. A ação aproximou os idosos, proporcionou-lhes momentos catárticos, em que liberaram suas emoções e ficaram mais sociáveis, e melhorou seu relacionamento interpessoal.

É importante ressaltar que, no universo de uma ILPI, existem muitas situações e idosos com vivências distintas, com suas particularidades, porquanto são sujeitos singulares. Dentro 
dessas particularidades, é importante selecionar o tipo de ação adequada para cada idoso. Paes (2007) aponta essas diferentes possibilidades ao relatar as atividades realizadas na Sociedade Porto-alegrense de Auxílio aos Necessitados (SPAAN) e mostrou como as histórias e as atividades musicais podem melhorar a qualidade de vida de idosos moradores de instituições de longa permanência. Para isso, utilizou o estudo de caso de quatro pessoas internandas na SPAAN. A partir dessa pesquisa, em que foi empregada uma entrevista semiestruturada, a pesquisadora constatou que há receptividade parcial para as leituras e que é possível estabelecer vínculos de afeto entre todos os sujeitos e o mediador das narrativas literárias emusicais.

\footnotetext{
A narrativa musical, através da mediação da linguagem, interage com o nosso imaginário. Por essa via, podemos atualizar e reordenar as nossas impressões e as imagens sobre a realidade presente e, assim, provocar modificações nas nossas representações sobre o tempo passado. (MORIGI; BONOTTO, 2004, p. 148).
}

Entende-se que a leitura tem diferentes vertentes, e uma delas é a musical, um dispositivo que pode ser utilizado para promover interação, memorização, criação e atividade terapêutica. Considerada como um instrumento terapêutico, a música - tanto os diferentes sons quanto sua letra - pode desencadear diferentes emoções nos idosos, atuar nos sentidos, alternar sentimentos, despertá-los, tranquilizar ou agitar, entristecer ou alegrar ou até mesmo despertar no indivíduo recordações saudosas, provocar reflexão e inspiração e estimular a criatividade.

No que diz respeito à especificidade terapêutica que envolve a música, pode-se citar a musicoterapia que, segundo Bruscia (2000), é a utilização de sons e de elementos para qualificar e proporcionar ganhos terapêuticos. Os procedimentos e a metodologia utilizados nessa técnica variam conforme a linha, a abordagem,os objetivos da terapia desenvolvida e as necessidades particulares de cada pessoa ou do grupo atendido. As experiências com as músicas utilizadas divergem de acordo com a audição, a recriação, a improvisação e a composição, que podem ser aplicadas juntas ou separadas.

A pesquisa de Marin (2014) apresenta outra vertente importante da mediação da leitura que envolve a memória. A pesquisadora investigou as memórias de leitura de cidadãos idosos residentes na cidade de Veranópolis, no Rio Grande do Sul, e abordou experiências de leitura dos idosos, incluindo leitura oralizada e do impresso. A técnica utilizada para alcançar esse propósito foi a da história oral, em que foram realizadas entrevistas com os idosos e registradas as memórias de leitura dessa população. $\mathrm{O}$ estudo mostrou que cada indivíduo tem uma memória única e pessoal dos acontecimentos vividos, o que demonstra o quão holístico é o universo dosidosos. 
Vetter (2005, p. 34) assevera que, “[...] quando recorremos à memória, temos uma representação do passado, da tradição, da história do nosso povo." Dessa maneira, é possível perceber as diferentes possibilidades e os benefícios decorrentes das atividades de leitura. A mediação da leitura que envolve a memória pode proporcionar ao idoso reviver fatos, rememorar momentos alegres e tristes, reativar lembranças de sua vida, portanto, também poderá ter uma finalidadeterapêutica.

Mota, Pereira e Rodrigues (2014) também apresentam, em sua pesquisa, aspectos que demonstram a importância das ações de mediação da leitura. O estudo foi feito com idosas do grupo 'Circuleiturando', para verificar as práticas de leitura desenvolvidas nos círculos de leitura, mediante a recepção do texto literário e as trocas de experiências. Essas observações possibilitaram a socialização e o fortalecimento da solidariedade no grupo. Foi constatado que as atividades desenvolvidas com os textos no círculo de leitura foram importantes para estimular os diversos tipos de memória e mecanismos cognitivos, estimular a competência comunicativa e ativar aimaginação.

\begin{abstract}
A leitura envolve, por definição, a memória visual e a verbal; nos deficientes visuais, a memória auditiva e a verbal. Os dois sentidos mais importantes para os humanos são a visão e a audição. Além da memória visual ou auditiva e verbal, a leitura envolve a memória de imagens. Impossível ler a palavra 'árvore' sem que desfilem pela mente algumas das muitas árvores que conhecemos ao longo de nossa vida. Impossível ler a palavra 'casa' sem lembrar de pelo menos duas, aquela em que transcorreu nossa infância e a atual. (IZQUIERDO, 2013, p. 86).
\end{abstract}

Assim, as ações de mediação da leitura podem contribuir para estimular a parte cognitiva, a motora e a fonética da pessoa idosa e auxiliar o tratamento de determinadas enfermidades.

Na literatura sobre a Ciência da Informação, existem trabalhos em que o idoso também é referido como mediador. Isso significa que, nas atividades de mediação da leitura, ele pode atuar como protagonista. Para elucidar isso, Franciscati e Fernandes (2018) realizaram um estudo que visou representar, por meio da obra Por Parte de Pai, de Bartolomeu Campos selecionada pelo Programa Nacional Biblioteca na Escola PNBE, a relação entre avós e netos que, mesmo em diferentes faixas etárias, conseguem promover elos igualitários e estabelecer uma coeducação de gerações. A pesquisa mostrou que os idosos/avós têm exercido o papel de mediadores de leitura em relação ao seu neto. Ainda segundo os autores, com o desenvolvimento dessa atividade, pode-se obter como resultado o lugar de fala desses indivíduos, para que possam se expressar e explorar suas narrativas e perspectivas diante das situações, elucidando as diferenças que podem ser encontradas nas diferentes gerações. Assim, 
a leitura pode ser mediada de várias formas, respaudada em práticas e experiências, como também fundamentada em distintos embasamentos teóricos e empíricos das diversas áreas do conhecimento, o que contribui para que o idoso seja o protagonista dessas ações.

\section{Considerações finais}

O envelhecimento é um período de mudanças biopsicossociais, e a maneira como deve ser enfrentado depende das condições culturais, sociais e físicas de cada pessoa. Em relação à saúde do idoso, no que se refere à interação social, muitos deles têm dificuldade de conseguir estabelecer vínculos afetivos e relacionamentos sociais. Nesse sentido, esta pesquisa evidenciou que as atividades de mediação da leitura podem contribuir para melhorar a realidade dos idosos.

A partir das reflexões apresentadas por meio da literatura da Ciência da Informação, no que tange a mediação da leitura para os idosos, foi possível constatar que essa ação envolve um processo interativo que contribui para o desenvolvimento dos idosos e, sobretudo, para atribuírem sentidos ao que leem. Na leitura mediada por sujeitos e dispositivos, é possível ampliar a compreensão de mundo e atribuir sentido às vivências. Assim, por meio da mediação da leitura, os idosos podem agir com os mediadores, ressignificando suas ações, atribuindo sentido as suas práticas e as relações sociais que constituíram durante a vida.

A mediação da leitura é uma atividade que exige do mediador atitude, disposição e receptividade. Isso requer a percepção dos gostos, dos desejos, das preferências, das dificuldades e dos saberes de cada idoso mediado. É necessário ter essa sensibilidade sobre o grupo mediado e entender a individualidade e a maneira como cada um enxerga o mundo e se relaciona com ele. Durante a mediação, é importante proporcionar segurança para os idosos e deixá-los confortáveis para o desenvolvimento da atividade proposta. Dessa forma, os mediadores podem observar a necessidade de se comunicar para entender as diferentes demandas e a comunicação reflexiva e interpessoal.

Com base no que foi apresentado, considera- se que o desenvolvimento dessas ações é de fundamental importância para ressignificar a vida dos idosos e estimulá-los a compartilhar seus conhecimentos e sentimentos, a interagir, a vivenciar novas experiências e sentir o prazer de vivê-las e a atuar em favor do outro e do bem coletivo. Entretanto, para que esses resultados sejam alcançados de maneira efetiva, o mediador da leitura deve ter consciência de suas ações e, entre outros fatores, fazer um planejamento e constituir uma equipe multidisciplinar atuante. 
O mediador que tem consciência de sua responsabilidade social é aquele que facilita o processo de aproximar o idoso do dispositivo a ser lido, interpretado e apropriado, agindo de maneira acolhedora e adotando um olhar e uma escuta sensíveis, apoiando o idoso para que desenvolva o prazer pela leitura. Para que isso aconteça de maneira satisfatória, é importante haver um processo dialógico entre o mediador e o idoso, considerando diferentes aspectos, inclusive os relacionados ao contexto de vida em que o idoso está inserido.

\section{Referências}

BORTOLIN, Sueli. Mediação oral da literatura: a voz dos bibliotecários lendo ou narrando. 2010. Tese (Doutorado em Ciência da Informação) - Universidade Estadual Paulista, Marília, 2010. Disponível em: https://repositorio.unesp.br/handle/11449/103349. Acesso em: 17 jan. 2020 .

BOSO, Augiza Karla et al. Aspectos cognitivos da leitura: conhecimento prévio e teoria dos esquemas. Revista ACB: Biblioteconomia em Santa Catarina, Florianópolis, v. 15, n. 2, p. 24-39, jul./dez., 2010.

BRUSCIA, Kenneth. Definindo musicoterapia.Rio de Janeiro: Enelivros, 2000.

COSTA, Clarissa Benassi Gonçalves da; BORTOLIN, Sueli. A terceira idade e as ações de leitura dos bibliotecários de duas instituições. In:SEMINÁRIO EM CIÊNCIA DA INFORMAÇÃO, 2., 2007, Londrina. Anais eletrônicos [...]. Londrina:Universidade Estadual de Londrina, 2007.

CUNHA, Cristiano. Planejamento estratégico: uma abordagem prática. Publicação do NEST- Núcleo de Estudos - Departamento de Engenharia de Produção e Sistemas, Universidade Federal de Santa Catarina. Florianópolis,1996.

FRANCISCATI, Jéssica de Barros; FERNANDES, Célia Regina Delácio. Coeducação de gerações: representação de avós mediadores de leitura na obra "Por Parte de Pai". Revista Educação e Emancipação, São Luís, v. 11, n. 2, maio/ago. 2018. Disponível em: http://www.periodicoseletronicos.ufma.br/index.php/reducacaoemancipacao/about/contact. Acesso em: 17 jan. 2020.

FREIRE, Paulo. Conscientização: teoria e prática da libertação: uma introdução ao pensamento de Paulo Freire. São Paulo: Centauro, 2008.

INSTITUTO BRASILEIRO DE GEOGRAFIA E ESTATÍSTICA [IBGE]. Número de 2007. Disponível em: http://eprints.rclis.org/13267/. Acesso em: 2 jan. 2020.

GIACUMUZZI, Gabriela da Silva et al. Projeto de leitura Vivendo Histórias: vivendo a inclusão por meio da leitura numa casa geriátrica. Revista Brasileira de Biblioteconomia e Documentação, São Paulo, v. 10, ago. 2014. Disponível em:

https://rbbd.febab.org.br/rbbd/article/view/319. Acesso em: 17 jan. 2020. 
GIL, Antônio Carlos. Como elaborar projetos de pesquisa. 5.ed. São Paulo: Atlas.2010.

INDURSKY, Freda; ZINN, Maria Alice Kaner. Leitura como suporte para a produção textual. Revistas Leitura Teoria e Prática, Campinas, n. 5, 1985.

IZQUIERDO, Iván. Questões sobre memória.5. ed. São Leopoldo, Unisinos, 2013.

JERÔNIMO, Viviane et al. Biblioterapia na melhor idade. Revista ACB: Biblioteconomia em Santa Catarina, Florianópolis, v. 17, n. 2, p. 460-471, jul./dez. 2012.Disponível em: http://www.brapci.inf.br/index.php/article/view/0000012007/3239868cb958256c8bebcae6b74 25858. Acesso em: 1 dez.2019.

MARIN, Janaina Carobin. Hábitos de leitura de idosos de Veranópolis - RS: estudo sobre memórias. 2014. 82 f. Monografia (Bacharelado em Biblioteconomia) - Instituto de Ciências Humanas e da Informação, Universidade Federal do Rio Grande, Rio Grande, 2014.

Disponível em:

http://repositorio.furg.br/bitstream/handle/1/5883/H\%c3\%albitos\%20de\%20leitura\%20de\%2 0idosos\%20de\%20Veran\%c3\%b3polis\%20\%e2\%80\%93\%20RS\%20estudo\%20sobre\%20me m\%c3\%b3rias.pdf? sequence=.1. Acesso em: 1 dez. 2019.

MELO, Vanessa Martins de; MORO, Eliane Lourdes da Silva; TRESSINO, Camila Schoffen. Projeto de Leitura VIVendo Histórias. In: SEMINÁRIO NACIONAL DE BIBLIOTECAS EM BRAILE, 7., 2011, Campinas, Anais [...]. Campinas: UNICAMP, 2011.

MORIGI, Valdir José; BONOTTO, Martha E. K. Kling. A narrativa musical, memória e fonte de informação afetiva. Em Questão, Porto Alegre, v. 10, n. 1, p. 143-161, jan./jun. 2004. Disponível em: https://seer.ufrgs.br/EmQuestao/article/view/88/47. Acesso em: 16 maio 2021.

MORO, Eliane Lourdes da Silva; ESTABEL, Lizandra Brasil. A mediação da leitura na família, na escola e na biblioteca através das tecnologias de informação e de comunicação e a inclusão social das pessoas com necessidades especiais. Revista Inclusão Social, Brasília, v. 4, n. 2, p. 67-81, jan./jun. 2011. Disponível em:

http://revista.ibict.br/inclusao/article/view/1657. Acesso em: 16 mar. 2021.

MOTA, Kátia Maria Santos; PEREIRA, Aurea Silva da; RODRIGUES, Maria Emiília Oliveira Santana de. Leituras compartilhadas, memória e envelhecimento. Revista da FAEEBA: Educação e Contemporaneidade, Salvador, v. 23, n. 41, p. 105-116, jan./jun. 2014. Disponível em: https://www.revistas.uneb.br/index.php/faeeba/article/view/827/585. Acesso em: 16 mar. 2021.

NEVES, Iara Conceição Bitencourt. A leitura como prática pedagógica na formação do profissional da informação. In: SANTOS, Jussara Pereira (Org.). A leitura como prática pedagógica.Rio de Janeiro: Fundação Biblioteca Nacional, 2007. p.17-31.

ORLICKAS, Elizen da. Modelos de gestão: das teorias da administração à gestão estratégica. São Paulo: IBPEX, 2010.

PAES, Camila da Rocha. Idosos moradores de instituição de longa permanência e a influência das narrativas literárias e musicais:estudo de caso. 2007. 85 f. Monografia 
(Bacharelado em Biblioteconomia) - Departamento de Ciência da Informação, Faculdade de Biblioteconomia e Comunicação, Universidade Federal do Rio Grande do Sul, Porto Alegre, 2007. Disponível em:

https://lume.ufrgs.br/bitstream/handle/10183/18709/000666830.pdf? sequence=1\&isAllowed= y. Acesso em: 16 mar. 2021.

PINHEIRO, Edna Gomes. Biblioterapia para o idoso: Projeto Renascer: um relato de experiência. Informação \& Sociedade: estudos, João Pessoa, v. 8, n. 1, p. 155- 163, 1998. Disponivel em:

http://www.brapci.inf.br/index.php/article/view/0000002763/77cbd4903e212f46dc445eeec93 6944a. Acesso em: 29 dez. 2019.

RASTELI, Alessandro. Mediação da leitura em bibliotecas públicas. 2013. Dissertação (Mestrado em Ciência da Informação) - Universidade Estadual Paulista, São Paulo, 2013. Disponível em: https://www.marilia.unesp.br/Home/Pos-

Graduacao/CienciadaInformacao/Dissertacoes/rasteli_a_me_mar.pdf. Acesso em: 22 set. 2019.

RÊGO, Raimunda Queiroz; SAMPAIO, Maria Lúcia Pessoa. Estratégias de mediação da leitura com adultos/idosos no espaço informal. In: FÓRUM INTERNACIONAL DE PEDAGOGIA, 6., 2014, Santa Maria. Anais... Santa Maria: FIPED, 2014. p. 112.

SANTOS, Marcus Vinícius Machado dos. A leitura como prática cotidiana e motivacional: da infância ao crescimento intelectual e discernimento crítico. Revista ACB: Biblioteconomia em Santa Catarina, Florianópolis, v.11, n.1, p. 29- 37, nov. 2006. Disponível em: https://revista.acbsc.org.br/racb/article/view/462/580.

SANTOS, Raquel do Rosário; RIBEIRO, Iveth da Costa; SOUSA, Ana Cláudia Medeiros de. A biblioteca pública como ambiente de mediação da informação para o usuário da terceira idade. Informação \& Informação, Londrina, v. 24, n. 1, p. 442-457, mar. 2019.Disponível em: http://www.uel.br/revistas/uel/index.php/informacao/article/view/32222. Acesso em: 17 jan. 2020.

THOMAZ, Fabiane; VALENCIA, Maria Cristina Palhares. Inclusão social do idoso através da leitura. CRB8 Digital, São Paulo, v. 1, n. 5, p.148-160, 2012. Disponível em: http://hdl.handle.net/20.500.11959/brapci/9897. Acesso em: 17 jan. 2020.

VETTER, Silvana Maria de Jesus. Memórias de leitura de pessoas idosas.2005. $145 \mathrm{f}$. Dissertação (Mestrado em Educação) - Universidade Federal do Maranhão, São Luís, 2005. Disponível em: http://tedebc.ufma.br:8080/jspui/bitstream/tede/272/1/silvana\%20vetter.pdf. Acesso em: 4 jun. 2019. 